\title{
British Standard and Euro Code: Model of Singly Reinforced Rectangular Concrete Under Actions
}

\author{
*Okeniyi, A.G, Alli, O. O, Amusat, T. A and Akolade, A.S \\ Department of Civil Engineering, The Polytechnic, Ibadan, Ibadan, Nigeria.
}

\begin{abstract}
Upgrading are desired Changes on any standard in operation. Meanwhile context understanding are required to achieve positive impact on the subject system. In same vein, codes of practice are always revised and that users should be made to use the latest edition of any relevant standard. Thus a model is developed to describe the sectional analysis difference with predicting implications of various combinations of sectional dimensions in structural reinforced concrete elements with reference to the two codes. The method adopted is purely mathematical technique of modeling, concept and application. Based on the previous behavioural knowledge of such using BS code, Okeniyi et al (2012), a concrete rectangular section of singly reinforced status was also used as a case study. The section was analyzed from stress-strain relationship to formulate the governing equations and the same was specified by breadth $b$, total depth $h$ and moment of resistance $M_{R}$. This was simulated to describe the relationship between the variable parameters and predict the behavior of a rectangular section under loads with reference to British Standard and Euro Code. The model, thus defines clearly sectional analysis difference increasing understanding for better structural design skill.
\end{abstract}

Keywords: Reinforced Concrete, Stress-Strain Relationship, Rectangular Section and Moment of Resistance

DOI: $10.7176 / \mathrm{CER} / 12-6-05$

Publication date:June $30^{\text {th }} 2020$

\subsection{INTRODUCTION}

British Standard and Euro Code are both civil engineering and building structural standards prepared as guide lines to cover structural design operations (Neville, 2000). Though the two provide clear and honest introduction to the basic principle and methods design for con The Issues and communications between structural engineers about a particular element is usually its behaviour under actions of load. Hence, the first of the objectives of the most recent methods of structural design known as 'limit state' emphasized that a particular engineering structure must be safe under worst condition of loadings. This requirement among others must be met, no matter how difficult the task of estimating the loads and variation in the strength of the concrete and steel. ( Khurumi, 2009)

Accepting human limitation upon estimations and calculations of design data, the use of factors of safety is considered to achieve safe and durable structures. However, possession of adequate data, knowledge of materials characteristic and other design information is not exhaustive. Substantive skill in design procedure and understanding of the dimensional combination implications of a particular element under a set of imposed actions (loads) is also crucial. Analysis of a structural element at the ultimate limit state is normally performed for loadings corresponding to that state.

A reinforced concrete structure consists of bending (horizontal) elements and compressive (vertical) elements. Generally, bending elements are slabs and beams, while compressive elements are columns and walls. They are rigidly connected together to form a monolithic frame. Thus each of the elements/members must be designed to be capable of resisting the subjecting forces. Thus the first challenge faced by the designers is the selection of adequate dimension for a particular element under consideration. This paper therefore addressed the issue of reactive behavior of an element under actions at varying cross-sectional dimensions, with particular attention to beam. (Maginley and Choo, B.S.)

\subsection{METHODOLOGY}

Sectional analysis method was adopted to achieve satisfactory and economic design of a concrete structure. Mosley and Bungey (1990) and Mosley, et. al., (2007), method of analysis was followed to obtain the governing equation and also to define the problem. Singly reinforced rectangular section is as well considered under bending action at balance condition of ultimate limit state.

\subsection{The Governing Equation}

The behavior of structural concrete is normally represented by a parabolic stress block obtained from stress- strain relationship, but ultimate design stress is given by;

1) BS Code: Cube crushing strength, Mosley, W. H. and Bungey, J. H. (1990):

$$
\begin{aligned}
& \alpha_{\mathrm{b}} f_{\mathrm{cu}} / \mathrm{\gamma}_{\mathrm{c}}=0.67 f_{\mathrm{cu}} / 1.5 \\
& \text { Stress }=0.45 f_{\mathrm{cu}}
\end{aligned}
$$


2) Euro Code: Cylinder crushing strength, Mosley, W. H. et al (2007):

$$
\begin{aligned}
& \alpha_{\mathrm{r}} f_{\mathrm{ck}} / \gamma_{\mathrm{c}}=0.85 f_{\mathrm{ck}} / 1.5 \\
& \text { Stress }=0.567 f_{\mathrm{ck}}
\end{aligned}
$$

where; $\quad \alpha_{\mathrm{r}}=$ factor for bending strength and cylinder crushing strength disparity

$\alpha_{b}=$ factor for bending strength and cube crushing strength disparity

$f_{\mathrm{ck}}=f_{\mathrm{cu}}=$ characteristic strength of concrete

$\mathrm{Y}_{\mathrm{c}}=$ patial factor of safety.

Considering the stresses from cube and cylinder crushing strength in the analysis of a singly reinforced beam section under bending, Fig. 01 below.

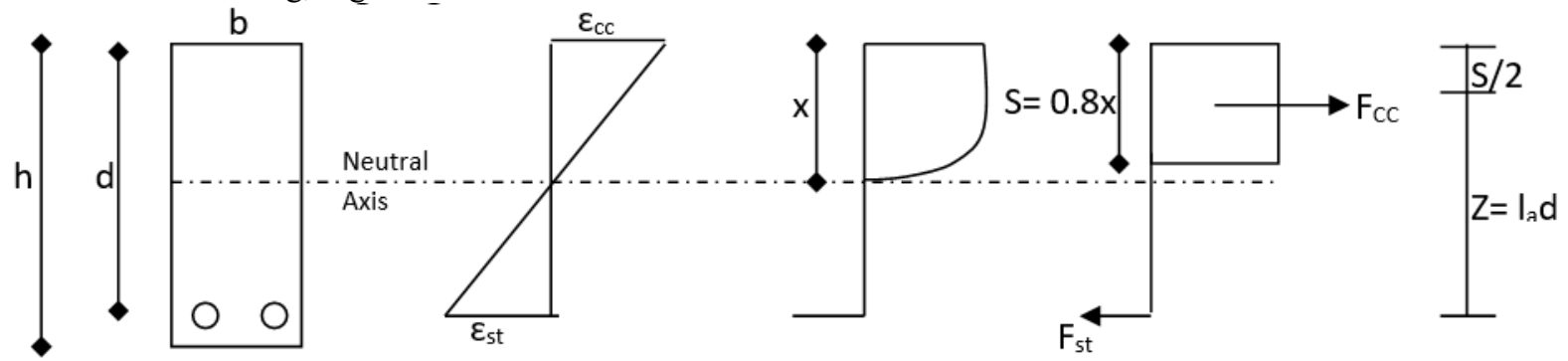
(a) Section
(b) Strain
(c) Stress block
(d) Simplified Stress block

Figure 01: Stress- strain block analysis

In this figure;

$$
\begin{aligned}
& \mathrm{h}=\text { total depth, } \\
& \mathrm{d}=\text { effective depth, } \\
& \mathrm{b}=\text { breadth, } \\
& \varepsilon_{\mathrm{cc}}=\text { maximum compressive strain of the concrete, } \\
& \varepsilon_{\mathrm{st}}=\text { strain in steel, } \mathrm{x}=\text { depth of compression, } \\
& \mathrm{s}=\text { depth of the simplified stress distribution, } \\
& \mathrm{F}_{\mathrm{cc}}=\text { resultant compressive force in concrete, } \\
& \mathrm{F}_{\mathrm{st}}=\text { resultant tensile force in reinforcing steel, } \\
& \mathrm{z}=\text { lever arm, } \\
& \mathrm{l}_{\mathrm{a}}=\mathrm{z} / \mathrm{d} \text { factor. }
\end{aligned}
$$

At ultimate limit state, it is important that member sections in flexure be ductile to ensure gradual failure of the structure instead of sudden catastrophic ones. According to Mosley W.H. et al (2007), this is achieved with gradual yielding of the tensile steel.

Hence, to achieve yielding of tension steel and other factors like hardness at ultimate limit state, depth of compression must be less or equals to $0.45 \mathrm{~d}$, i.e;

$$
\mathrm{X} \leq 0.45 \mathrm{~d}
$$

At equilibrium of this section, the ultimate design moment, $M$ must be equal to the the moment of resistance of the section, i.e

Where,

$$
\mathrm{M}_{\mathrm{R}}=\mathrm{F}_{\mathrm{cc}} \mathrm{Z}=\mathrm{F}_{\mathrm{st}} \mathrm{Z}
$$

$$
\begin{array}{lll} 
& & \mathrm{F}_{\mathrm{cc}}=\text { stress } \mathrm{x} \text { area of action } \\
\text { BS Code: } & \mathrm{F}_{\mathrm{cc}} & =0.45 \mathrm{f}_{\mathrm{cu}} \times \mathrm{bs} \\
\text { EC Code: } & \mathrm{F}_{\mathrm{cc}} & =0.567 f_{\mathrm{ck}} \times \mathrm{bs} \\
& & \text { and } \\
& & \mathrm{z}=\mathrm{d}-\mathrm{s} / 2 \\
& & \mathrm{~s}=2(\mathrm{~d}-\mathrm{z})
\end{array}
$$

Substituting equations (5) in (6),

$$
\text { BS Code: } \quad \mathrm{M}_{\mathrm{R}}=0.45 \mathrm{f}_{\mathrm{cu}} \text {. bs. } \mathrm{z}
$$$$
\text { EC Code: } \quad \mathrm{M}_{\mathrm{R}}=0.567 f_{\text {ck }} . \text { bs. } \mathrm{z}
$$

Substituting (6) in(7),

$$
\begin{array}{ll}
\text { BS Code: } & M_{R}=0.45 f_{c u} \cdot b \cdot 2(d-z) \cdot z \\
& M_{R}=0.9 f_{c u} \cdot b \cdot(d-z) \cdot z \\
\text { EC Code: } & M_{R}=1.134 f_{c k} \cdot b \cdot(d-z) . z
\end{array}
$$

According to BS 8110 (1999), upper limit of $z=0.95$ and lower limit of $z=0.775 d$ at maximum value of $x=$ $0.5 \mathrm{~d}$. While in EC2 (2006), upper limit of $\mathrm{z}=0.954$ and lower limit of $\mathrm{z}=0.82 \mathrm{~d}$ at maximum value of $\mathrm{x}=0.45 \mathrm{~d}$. Substituting;

$$
\text { BS Code: } \quad K=M / b d^{2} f_{c u}
$$




$$
\begin{array}{ll} 
& M=K_{b b d^{2} f_{c u}} \\
\text { EC Code: } & M=\operatorname{Kbd}^{2} f_{c k}
\end{array}
$$

Considering lower limits of $\mathrm{z}=0.775 \mathrm{~d}$ and $\mathrm{z}=0.82 \mathrm{~d}$ for $\mathrm{BS} \& \mathrm{EC}$ respectively and substitute in equations (8);

BS: $\quad M_{R}=0.9 f_{c u} \cdot b \cdot(d-0.775 d) .0 .775 d$

EC: $\quad \mathrm{M}_{\mathrm{R}}=1.134 f_{\mathrm{ck}} \cdot \mathrm{b} .(\mathrm{d}-0.82 \mathrm{~d}) .0 .82 \mathrm{~d}$

Ultimate Moment of Resistance;

$$
\begin{array}{ll}
\text { BS: } & M_{R}=0.156 f_{c u} b d^{2} . \\
\text { EC: } & M_{R}=0.167 f_{c k} b d^{2} .
\end{array}
$$

Equations (9.1) and (9.2) are the governing expressions for the model.

\subsection{RESULTS AND DISCUSSION}

\subsection{RESULTS}

Considering the model equation for a reinforced concrete beam made of $20 \mathrm{~N} / \mathrm{mm}^{2}$ and $410 \mathrm{~N} / \mathrm{mm}^{2}$ characteristic strengths of normal- weight concrete at 28 day of curing and steel respectively;

$$
\begin{array}{ll}
\text { BS: } & M_{R}=0.156(20) b d^{2} \\
& M_{R}=3.12 b^{2} \\
\text { EC: } & M_{R}=0.167(20) b d^{2} \\
& M_{R}=3.34 b^{2}
\end{array}
$$

\begin{tabular}{|c|c|c|c|c|}
\hline $\begin{array}{c}\text { Effective } \\
\text { Breadth, b }(\mathrm{mm}) \\
\end{array}$ & $\begin{array}{c}\text { Effective Depth, d } \\
(\mathrm{mm})\end{array}$ & $d^{2}\left(\mathbf{m m}^{2}\right)$ & $\begin{array}{cl}\text { BS: } & M_{R}=3.12 b d^{2} \\
& (k N m)\end{array}$ & $\begin{array}{c}\text { EC: } \begin{array}{c}M_{R}=3.34 b^{2} \\
(k N m)\end{array} \\
\end{array}$ \\
\hline \multirow[t]{9}{*}{150} & 300 & 90000 & 42.12 & 45.09 \\
\hline & 350 & 122500 & 57.33 & 61.37 \\
\hline & 400 & 160000 & 74.88 & 80.16 \\
\hline & 450 & 202500 & 94.77 & 101.45 \\
\hline & 500 & 250000 & 117.00 & 125.25 \\
\hline & 550 & 302500 & 141.57 & 151.55 \\
\hline & 600 & 360000 & 168.48 & 180.36 \\
\hline & 650 & 422500 & 197.73 & 211.67 \\
\hline & 700 & 490000 & 229.32 & 245.49 \\
\hline \multirow[t]{9}{*}{200} & 300 & 90000 & 56.15 & 60.11 \\
\hline & 350 & 122500 & 76.44 & 81.83 \\
\hline & 400 & 160000 & 99.84 & 106.88 \\
\hline & 450 & 202500 & 126.36 & 135.27 \\
\hline & 500 & 250000 & 156.00 & 167.00 \\
\hline & 550 & 302500 & 188.76 & 202.07 \\
\hline & 600 & 360000 & 224.64 & 240.48 \\
\hline & 650 & 422500 & 263.64 & 282.23 \\
\hline & 700 & 490000 & 305.76 & 327.32 \\
\hline \multirow[t]{9}{*}{250} & 300 & 90000 & 70.20 & 75.15 \\
\hline & 350 & 122500 & 95.55 & 102.29 \\
\hline & 400 & 160000 & 124.80 & 133.60 \\
\hline & 450 & 202500 & 157.95 & 169.09 \\
\hline & 500 & 250000 & 195.00 & 208.75 \\
\hline & 550 & 302500 & 235.95 & 252.59 \\
\hline & 600 & 360000 & 280.80 & 300.60 \\
\hline & 650 & 422500 & 329.55 & 352.79 \\
\hline & 700 & 490000 & 382.20 & 409.15 \\
\hline \multirow[t]{7}{*}{300} & 300 & 90000 & 84.24 & 90.18 \\
\hline & 350 & 122500 & 114.66 & 122.75 \\
\hline & 400 & 160000 & 149.76 & 160.32 \\
\hline & 450 & 202500 & 189.54 & 202.91 \\
\hline & 500 & 250000 & 234.00 & 250.50 \\
\hline & 550 & 302500 & 283.14 & 303.11 \\
\hline & 600 & 360000 & 336.96 & 360.72 \\
\hline
\end{tabular}

Simulating dimensional implication of $150,200,250$ and $300 \mathrm{~mm}$ breadth, b of the element on stability potential in terms of moment of resistance at varying depth, $\mathrm{d}$ of 300, 350, 400, 450, 500, 550, 600, 650 and 700mm using equation (10.1) and (10.2) above. Regular increase of 50mm input (additional) in breadth resulted in a decreasing additional of the moment of resistance in both design codes. This is shown in Tables and figures below.

Table 1 Moment Resistance for BS and EC at varying parameters 


\begin{tabular}{|c|c|c|c|c|}
\hline $\begin{array}{c}\text { Effective } \\
\text { Breadth, b (mm) }\end{array}$ & $\begin{array}{c}\text { Effective Depth, d } \\
(\mathrm{mm})\end{array}$ & $d^{2}\left(m^{2}\right)$ & $\begin{array}{cc}\text { BS: } & M_{R}=3.12 b^{2} \\
& (k N m)\end{array}$ & $\begin{array}{c}\text { EC: } \begin{array}{c}M_{R}=3.34 b d^{2} \\
(k N m)\end{array} \\
\end{array}$ \\
\hline & $\begin{array}{l}650 \\
700 \\
\end{array}$ & $\begin{array}{l}422500 \\
490000\end{array}$ & $\begin{array}{l}395.46 \\
458.64\end{array}$ & $\begin{array}{l}423.33 \\
490.98\end{array}$ \\
\hline
\end{tabular}

Table 2: Moment of Resistance @ 150mm Eff. Breadth

\begin{tabular}{|c|c|c|c|c|}
\hline \multirow{2}{*}{$\begin{array}{l}\text { Eff. Depth, d } \\
(\mathrm{mm})\end{array}$} & \multicolumn{2}{|c|}{ 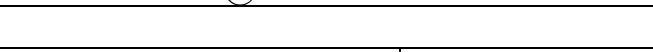 } & \multirow[b]{2}{*}{$\begin{array}{l}\text { Mmt. } \\
(\mathrm{kNm})\end{array}$ Of Resist. $\quad \mathrm{M}_{\mathrm{R}}$} & \multirow[b]{2}{*}{$\begin{array}{ll}\mathrm{M}_{\mathrm{R}} & \text { Diff. } \\
(\mathrm{kNm}) & \end{array}$} \\
\hline & $\begin{array}{l}\text { Mmt. Of Resist. } \quad M_{R} \\
(\mathrm{kNm})\end{array}$ & $\begin{array}{l}\mathrm{M}_{\mathrm{R}} . \\
(\mathrm{kNm})\end{array}$ & & \\
\hline 300 & 42.12 & - & 45.09 & - \\
\hline 350 & 57.35 & 15.21 & 61.37 & 16.28 \\
\hline 400 & 74.88 & $17.55(2.34)$ & 80.16 & 18.79(2.5) \\
\hline 450 & 94.77 & $19.89(2.34)$ & 101.45 & $21.29(2.5)$ \\
\hline 500 & 117.00 & $22.23(2.34)$ & 125.25 & $23.80(2.5)$ \\
\hline 550 & 141.57 & $24.57(2.34)$ & 151.55 & $26.30(2.5)$ \\
\hline 600 & 168.48 & $26.91(2.34)$ & 180.36 & $28,81(2.5)$ \\
\hline 650 & 197.73 & $29.25(2.34)$ & 211.67 & $31.31(2.5)$ \\
\hline 700 & 229.32 & $31.59(2.34)$ & 24549 & $33.82(2.5)$ \\
\hline
\end{tabular}

Table 3: Moment of Resistance @ 300mm Eff. Depth

\begin{tabular}{|c|c|c|c|c|}
\hline \multirow{2}{*}{$\begin{array}{l}\text { Breadth, b } \\
\quad(\mathrm{mm})\end{array}$} & \multicolumn{2}{|l|}{$\mathrm{BS}$} & \multicolumn{2}{|l|}{ EC } \\
\hline & $\begin{array}{l}\begin{array}{l}\text { Mmt. } \\
(\mathrm{kNm})\end{array} \\
\end{array}$ & $\begin{array}{l}\mathrm{M}_{\mathrm{R}} . \\
(\mathrm{kNm})\end{array}$ & $\begin{array}{l}\begin{array}{l}\text { Mmt. } \\
(\mathrm{kNm})\end{array} \\
\text { Of }\end{array}$ & $\begin{array}{ll}\mathrm{M}_{\mathrm{R}} . & \text { Diff. } \\
(\mathrm{kNm}) & \\
\end{array}$ \\
\hline 150 & 42.12 & - & 45.09 & - \\
\hline 200 & 56.15 & 14.03 & 60.11 & 15.09 \\
\hline 250 & 70.21 & 14.04 & 75.15 & 15.04 \\
\hline 300 & 84.21 & 14.00 & 90.18 & 15.03 \\
\hline
\end{tabular}

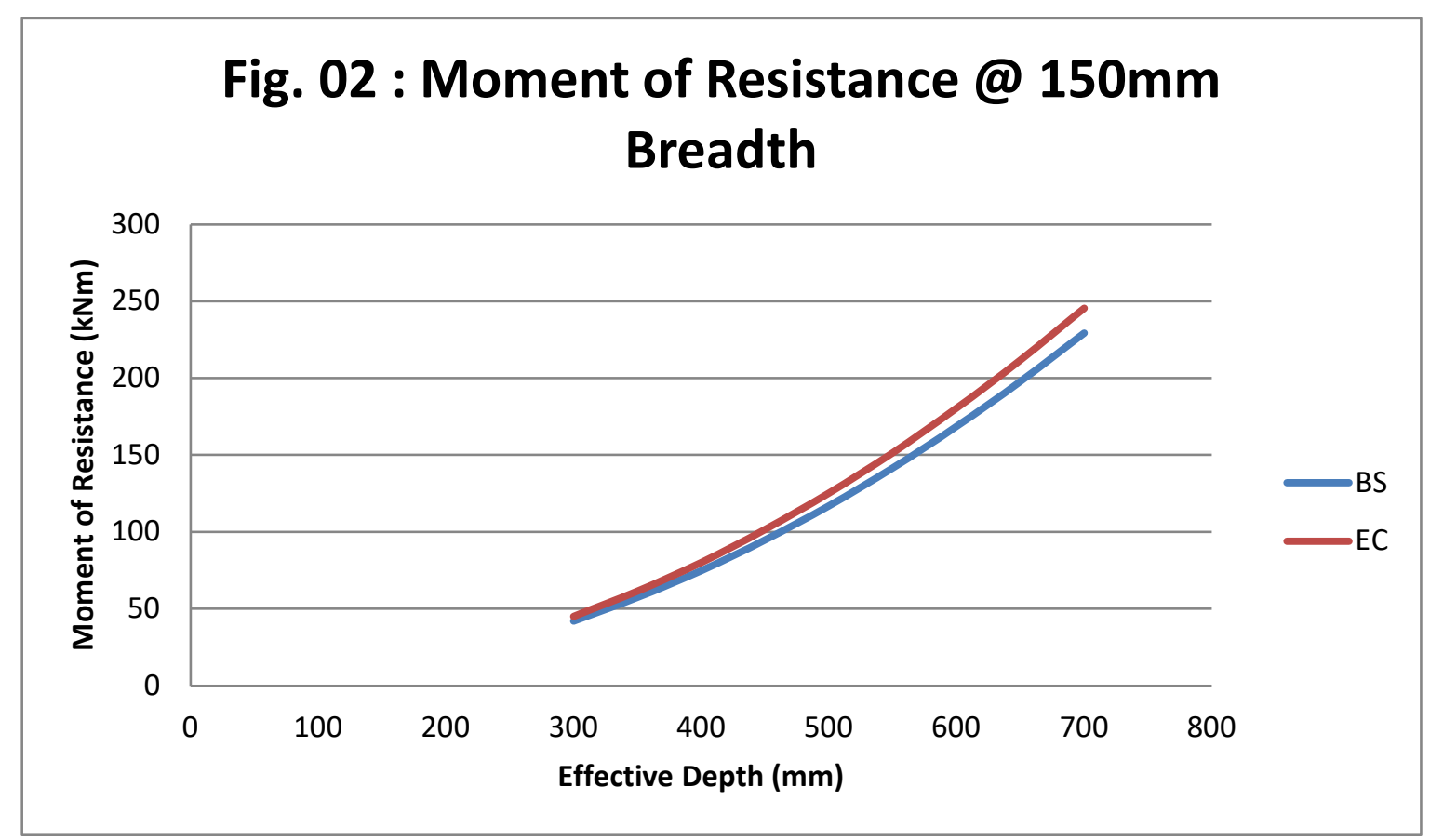


Fig. 03 : Moment of Resistance @ 200mm Breadth

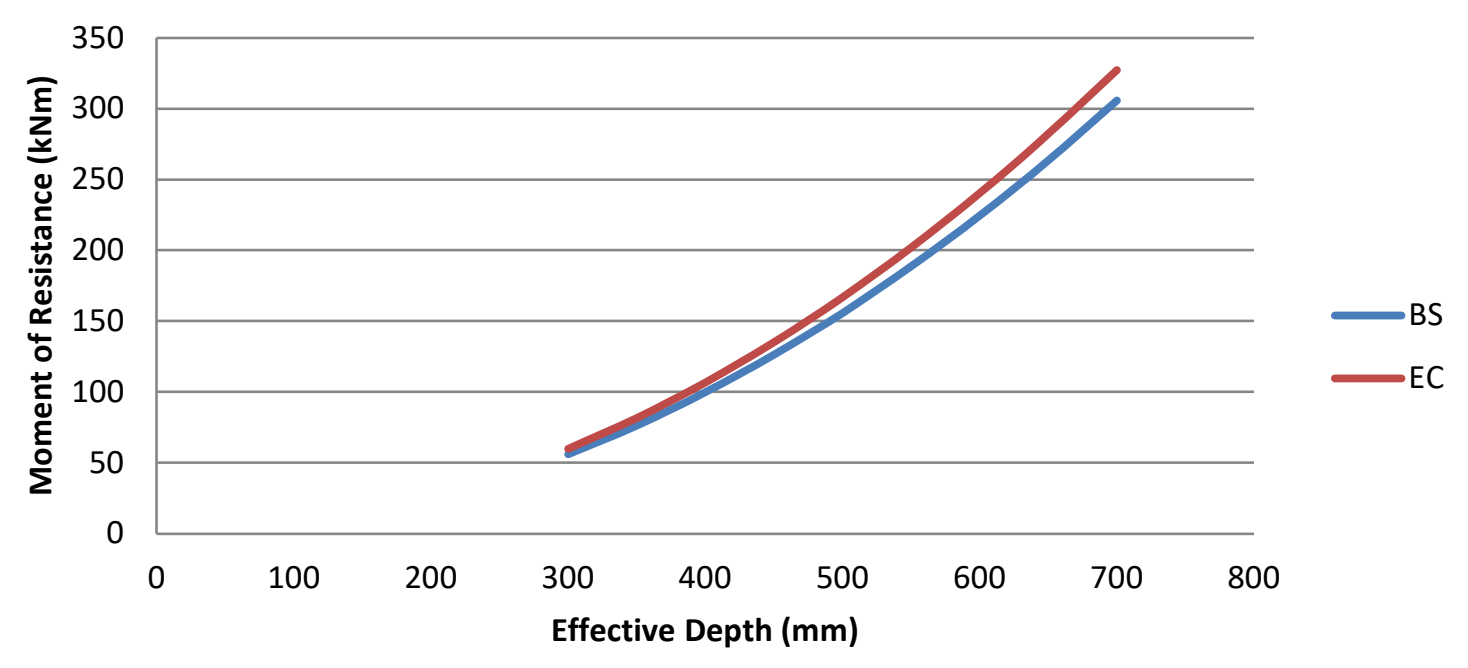

Fig. 04 : Moment of Resistance @ 250mm Breadth

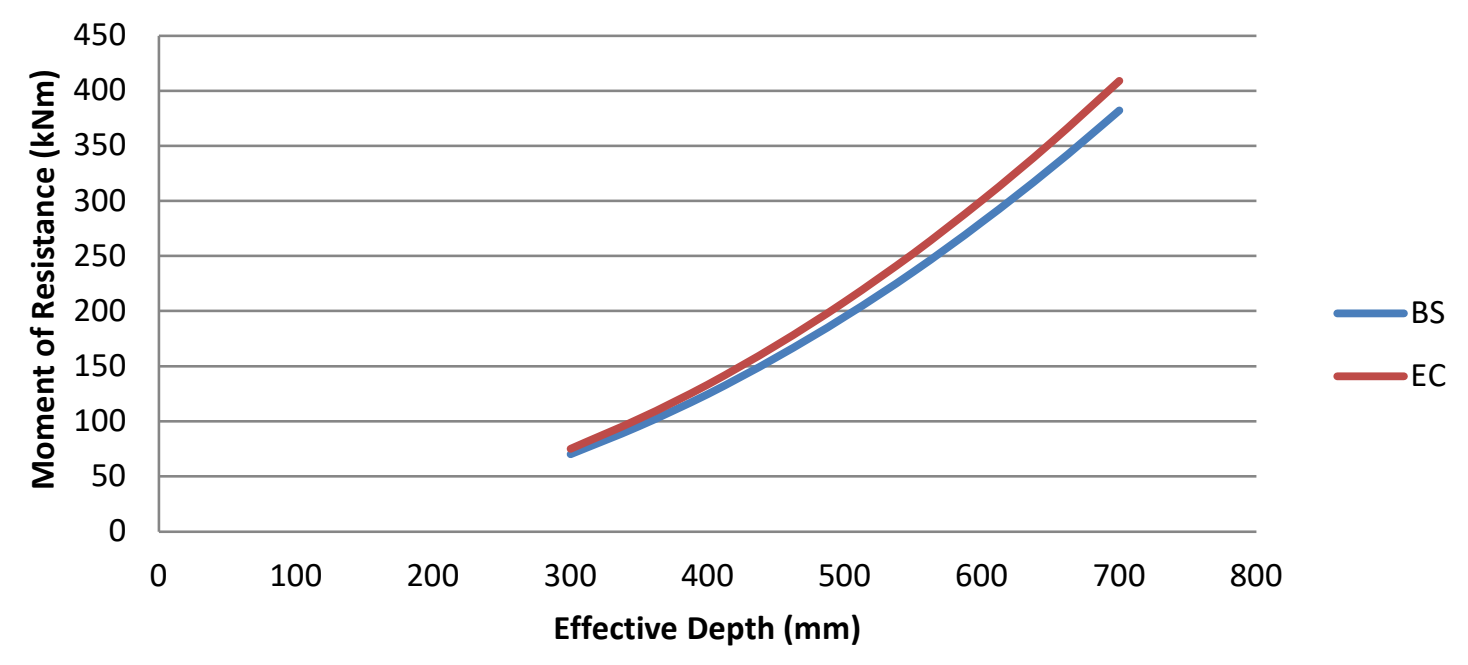


Fig. 05 : Moment of Resistance @ 300mm Breadth

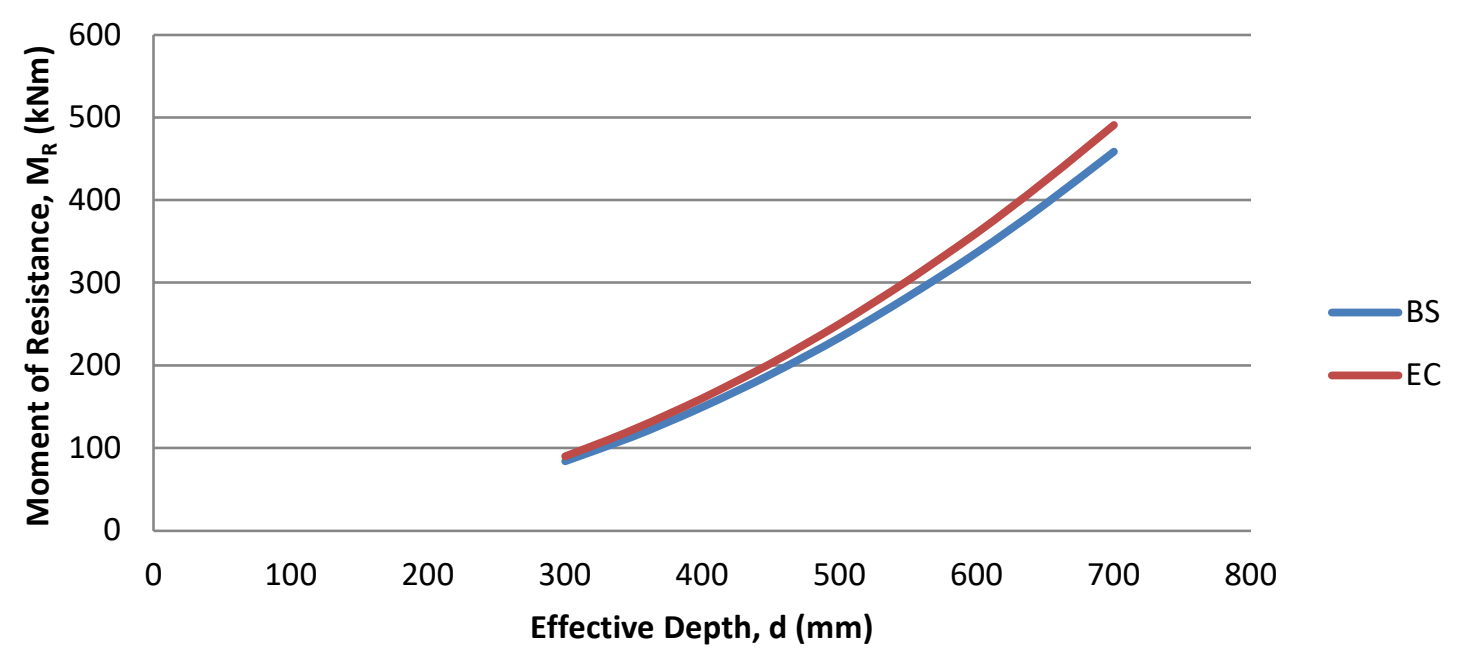

Fig. 06 : Moment of Resistance @ Varying Breadth with BS

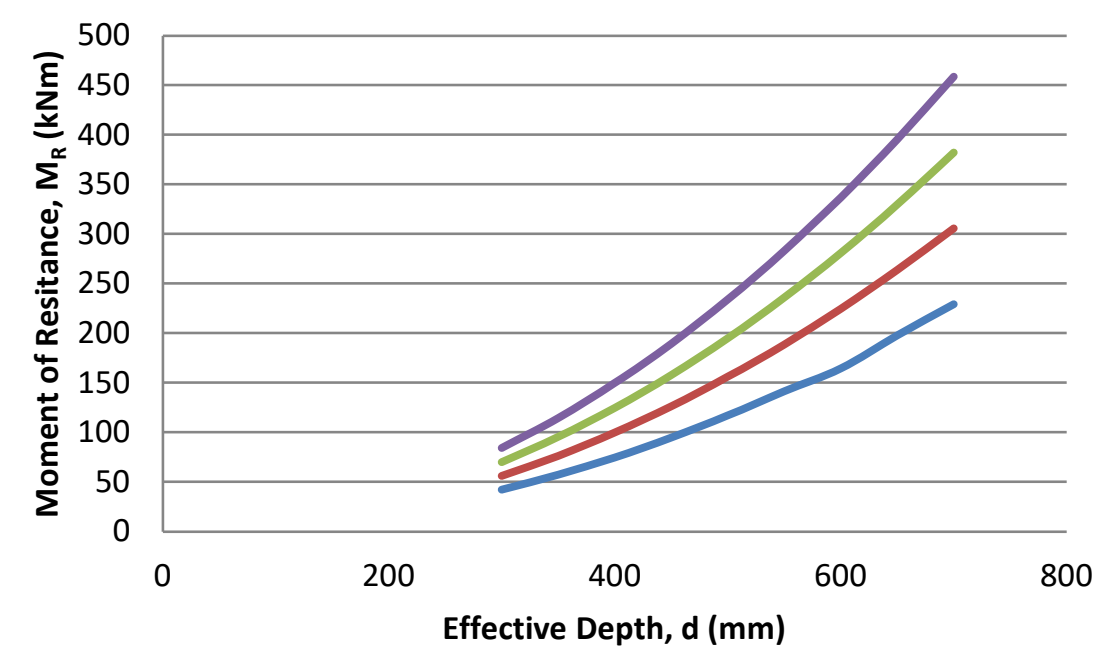

$150 \mathrm{~mm}$ Breadth

$200 \mathrm{~mm}$ breadth

$250 \mathrm{~mm}$ Breadth

$300 \mathrm{~mm}$ Breadth 

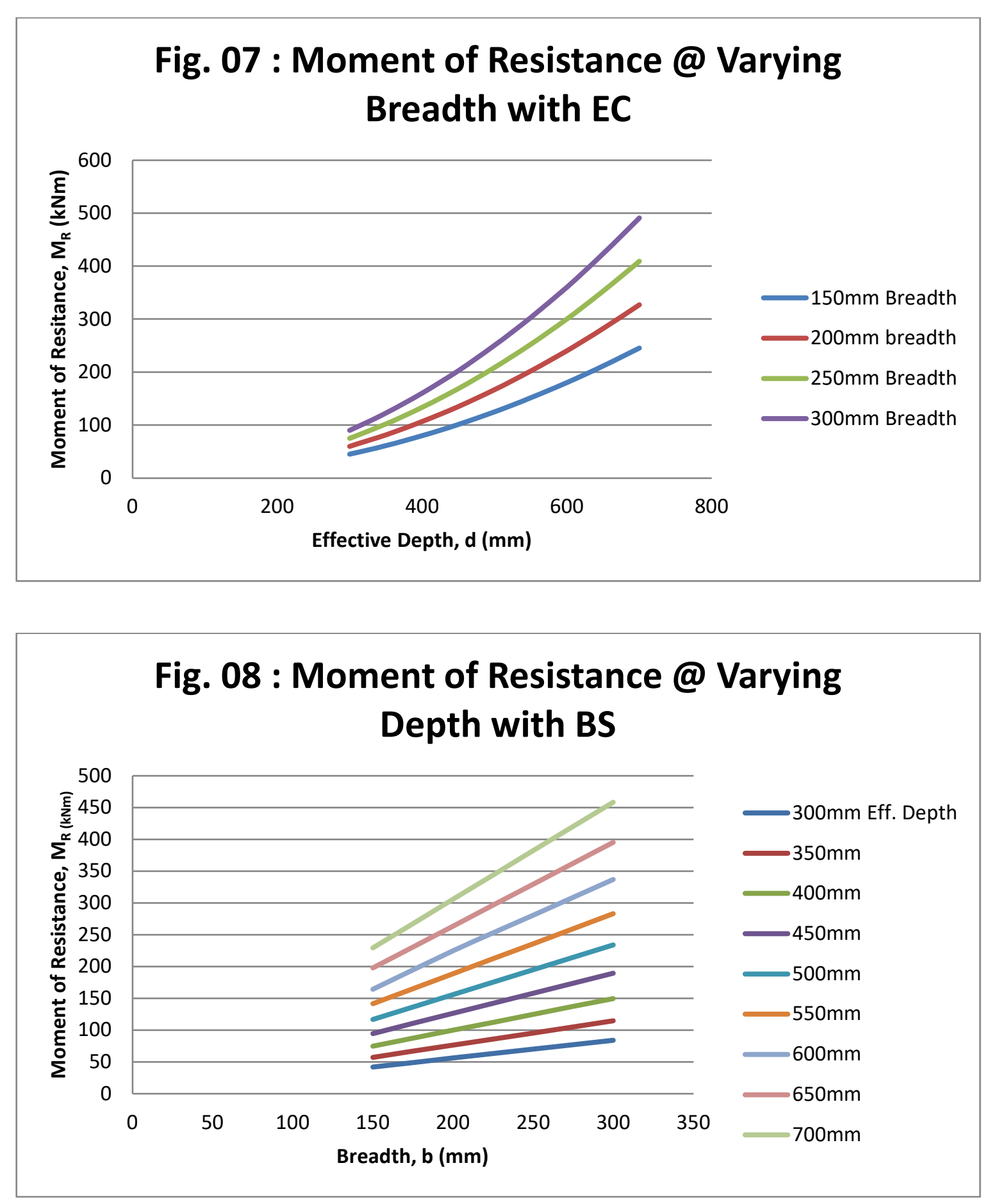


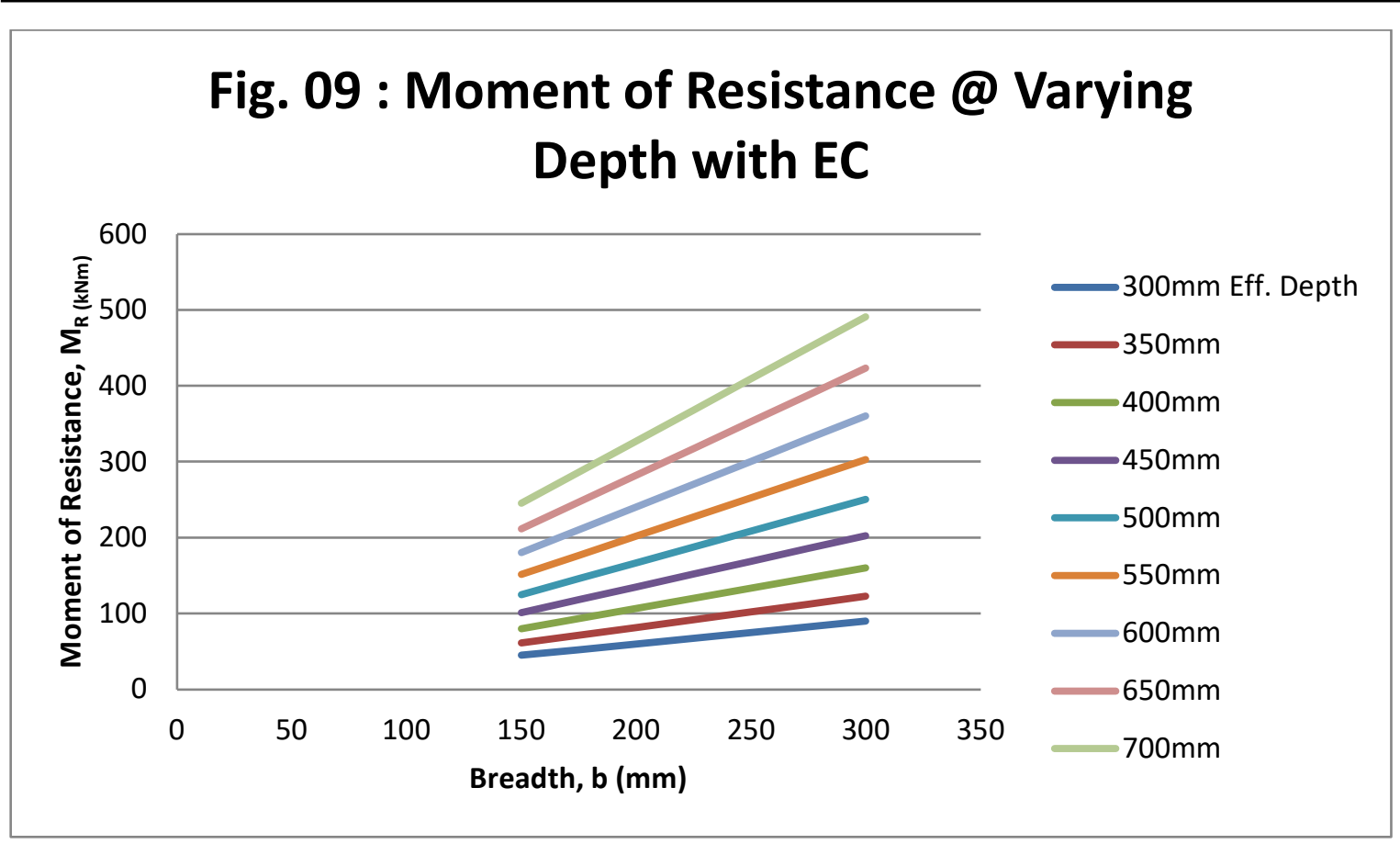

\subsection{DISCUSSION}

The fact still remains that reinforced concrete maintains durability quality in the world of construction activities. Experience overtimes had also established its versatility in terms of mould-ability to achieve a desired shape. The composite material is a combination of concrete and steel. Concrete is poor in tension but good in compression, durable at all conditions of exposure. Steel at the other hand, is good in tension, slender sections are poor in compression but possess good shear strength. Hence, combination of the two gives room for complimentary advantage over the short-comings, Morgan W. (1964) and Buckle I. G. (1979). On this basis, design of reinforced concrete structures are carried out with assumption that concrete does not resist tensile forces but designed to be transferred to steel through the bond between the interfaces of the two materials.

Structural members are purposed to carry loads, that which normally induce stresses and strains in materials of concrete and the reinforcing steel. However, consideration of the subjects is applied at the condition of equilibrium of the forces in concrete and steel. While resistance to the imposed moment is taken care of by material strength and sectional dimensions. Considering the table and figure above, Moment of resistance of rectangular beam increases at every increment in sectional dimension of breadth and depth respectively. Thus, breadth and depth are directly proportional to moment of resistance at varying capacity due to difference in power of degree of the two variables.

It is also noted in table $2 \& 3$ above, which equal magnitude of increment of the two variables produce different additional moment of resistance. As a result of this the figures generated by variable $d$ in the governing equation are curve graphs while that of variable $b$ are straight graphs, see fig. $06 \& 07$. The difference in the moment of resistance produced by the varying breadth, $b$ at a particular eff. depth is a constant value. For instance, at $300 \mathrm{~mm}$ eff. Depth, moment of resistance follows a consecutive addition of $14.0 \mathrm{kNm}$. However, in the case of variable $\mathrm{d}$ (depth) at a particular value of the breadth $\mathrm{b}$, the difference in moment of resistance is at an increasing trend. For instance, at $150 \mathrm{~mm}$ breadth, moment of resistance follows an increasing trend of $2.3 \mathrm{kNm}$.

\subsection{CONCLUSION AND RECOMMENDATION}

The results and tables above establish the consistency of the basic principle of stress-strain relationship of concrete materials and its sectional dimensional combinations implications of rectangular sections in structural design. By this knowledge, it is very easy to establish the magnitude of stress which can be safely supported by a particular dimensional combination. Thus in modern design, it is pertinent that a special care be taken at the time of designing a structure. That the same should be able to withstand the stresses under various load conditions in order to avoid failure.

For this reason, it is considered essential to have a complete data about the properties of the selected materials while designing a particular structure and appropriate prediction of the implications of dimensional combinations.

\section{REFERENCES}

A.G. Okeniyi, O.O. Alli and O.Y. Ojedokun (2012), Predictive Model of Moment of Resistance for Rectangular 
Reinforced Concrete Section under Actions. Journal of Civil and Environmental Research, International Institute for Science, Technology \& Education (IISTE). IISN 2225-0514 (online), Vol. 2 No.4

Khurumi, R.S. (2009), Strength of Materials, $23^{\text {rd }}$ Edition, S.Chard \& Company Ltd., Ram Nagar, New Delhi.

Mosley B., Bungey J. and Hulse, R. (2007), Reinforced Concrete Design, Sixth Edition, Book Power with Palgrave Macmillan, Houndmills, Basingstoke, Hampshire RG21 6XS.

Mosley B., and Bungey J. (1990), Reinforced Concrete Design, Forth Edition.

Maginley, T. J. and Choo, B.S. (1990), Reinforced Concrete, Second Edition.

Morgan, W. (1964) and Buckle I. G. (1979), The Elements of Structure, Second Edition.

Neville, A.M. (2000), Properties of Concrete, Forth Edition, Pearson Education Ltd, Essex. 